OPEN ACCESS

Edited by: Ying $X u$,

The State University of New York at Buffalo, USA

Reviewed by:

Maria Markaki,

Foundation for Research and Technology - Hellas, Greece

Vijay Karkal Hegde,

Texas Tech University, USA

*Correspondence:

Bin Li

libin_1971_2008@sina.com;

Zhongping An

tihhazp@sina.com:

Jinghua Wang

jhw8799@yahoo.com

Received: 06 April 2016 Accepted: 30 May 2016

Published: 16 June 2016

Citation:

Long X, Lou Y, Gu H, Guo X

Wang $T$, Zhu $Y$, Zhao $W$, Ning $X, L i$ B, Wang J and An Z (2016) Mortality,

Recurrence, and Dependency Rates Are Higher after Acute Ischemic Stroke in Elderly Patients with Diabetes Compared to Younger Patients. Front. Aging Neurosci. 8:142. doi: 10.3389/fnagi.2016.00142

\section{Mortality, Recurrence, and Dependency Rates Are Higher after Acute Ischemic Stroke in Elderly Patients with Diabetes Compared to Younger Patients}

\author{
Xue Long1,2, Yongzhong Lou', Hongfei Gu', Xiaofei Guo', Tao Wang ${ }^{1}$, Yanxia Zhu', \\ Wenjuan $\mathrm{ZhaO}^{3}$, Xianjia Ning ${ }^{4,5}$, Bin $\mathrm{Li}^{1,2 *}$, Jinghua Wang ${ }^{4,5 *}$ and Zhongping $\mathrm{An}^{3 *}$ \\ ${ }^{1}$ Department of Neurology, Tianjin Haibin People's Hospital, Tianjin, China, ${ }^{2}$ The Graduate School, Tianjin University of \\ Traditional Chinese Medicine, Tianjin, China, ${ }^{3}$ Department of Neurology, Tianiin Huanhu Hospital, Tianiin, China, \\ ${ }^{4}$ Department of Neurology, Tianjin Medical University General Hospital, Tianjin, China, ${ }^{5}$ Department of Epidemiology, Tianjin \\ Neurological Institute, Tianjin, China
}

Stroke has a greater effect on the elderly than on younger patients. However, the long-term outcomes associated with stroke among elderly patients with diabetes are unknown. We aimed to assess the differences in long-term outcomes between young and elderly stroke patients with diabetes. A total of 3,615 acute ischemic stroke patients with diabetes were recruited for this study between 2006 and 2014. Outcomes at 12 and 36 months after stroke (including mortality, recurrence, and dependency) were compared between younger (age $<75$ years) and elderly (age $\geq 75$ years) patients. The elderly group included 692 patients (19.1\%) overall. Elderly patients were more likely than younger patients to have a Trial of Org 10172 in Acute Stroke Treatment classification of stroke due to cardioembolism, moderate and severe stroke, and atrial fibrillation, but less likely to have hypertension and dyslipidemia, current smokers, and alcohol consumers. Mortality, dependency, and recurrence rates at 12 months after stroke were 19.0, 48.5, and $20.9 \%$ in the elderly group and $7.4,30.9$, and $15.4 \%$ in the younger group, respectively (all $P<0.05$ ). Corresponding rates at 36 months after stroke were $35.4,78.7$, and $53.8 \%$ in the elderly group and $13.7,61.7$, and $43.0 \%$ in the younger group, respectively (all $P<0.001$ ). The mortality, dependency, and recurrence rates at 12 and 36 months after stroke were significantly higher in the elderly group than in the younger group after adjusting for stroke subtypes, stroke severity, and risk factors. Odds ratios (95\% confidence interval) at 12 and 36 months after stroke were 2.18 (1.642.89 ) and 3.10 (2.35-4.08), respectively, for mortality, all $P<0.001 ; 1.81$ (1.49-2.20) and 2.04 (1.57-2.34), respectively, for dependency, all $P<0.001$; and 1.37 (1.06-1.76) and $1.40(1.07-1.85)$, respectively, for recurrence, $P=0.016$. The findings from this study suggest that management and secondary prevention should be emphasized in elderly patients with diabetes in China to reduce mortality, recurrence, and dependency after stroke.

Keywords: ischemic stroke, diabetes, outcomes, elderly, mortality, dependency, recurrence 


\section{INTRODUCTION}

Age is the most important non-modifiable risk factor for all subtypes of stroke, particularly ischemic stroke (MONICA Project (Monitoring Trends Determinants in Cardiovascular Disease), 1988; Feigin et al., 2014). The incidence of stroke more than doubles in each successive decade after the age of 55 years (MONICA Project (Monitoring Trends Determinants in Cardiovascular Disease), 1988). The age-standardized stroke incidence in low- and middle-income countries exceeds that in high-income countries by $21 \%$ in individuals $\geq 75$ years old, and age-standardized stroke mortality exceeds that in high-income countries by $33 \%$. In addition, the number of lost disabilityadjusted life-years is 1.5 times higher in low- and middleincome countries (Rothwell et al., 2005). China has experienced significant growth in its elderly population in recent decades; those $\geq 75$ years old accounted for $3.5 \%$ of the population in 2013 , and there were 200 million elderly residents $\geq 65$ years old in 2014 (National Bureaus of Statistics of the People's Republic of China, 2014; Peilin et al., 2014).
Population-based studies have indicated that $65 \%$ of all strokes occur in individuals $>65$ years old (MONICA Project (MONICA Project (Monitoring Trends Determinants in Cardiovascular Disease), 1988; Lloyd-Jones et al., 2009). Moreover, elderly patients have worse functional outcomes after stroke than do younger patients, and these differences persist even after adjusting for stroke risk factors and other comorbidities (Di Carlo et al., 1999; Kelly-Hayes et al., 2003; Bhalla et al., 2004; Kammersgaard et al., 2004; Palnum et al., 2008). A populationbased study demonstrated that the incidence of first-ever stroke increased by $4.3 \%$ annually in China among those $\geq 65$ years old from 1992 to 2012 (Wang et al., 2015).

It is well known that diabetes is significantly associated with stroke, and patients with diabetes mellitus (DM) are at greater risk of stroke than individuals without diabetes (Brott et al., 1989; Recommendations on Stroke Prevention, Diagnosis, and Therapy, 1989; Ullberg et al., 2015). A few studies have investigated the association between DM and longterm prognosis of patients following acute ischemic stroke (AIS; Rankin, 1957; Mahoney and Barthel, 1965); however, the

\section{0 acute ischemic stroke patients were recruited to this study, during the study periods.}

7715 patients without DM were excluded.

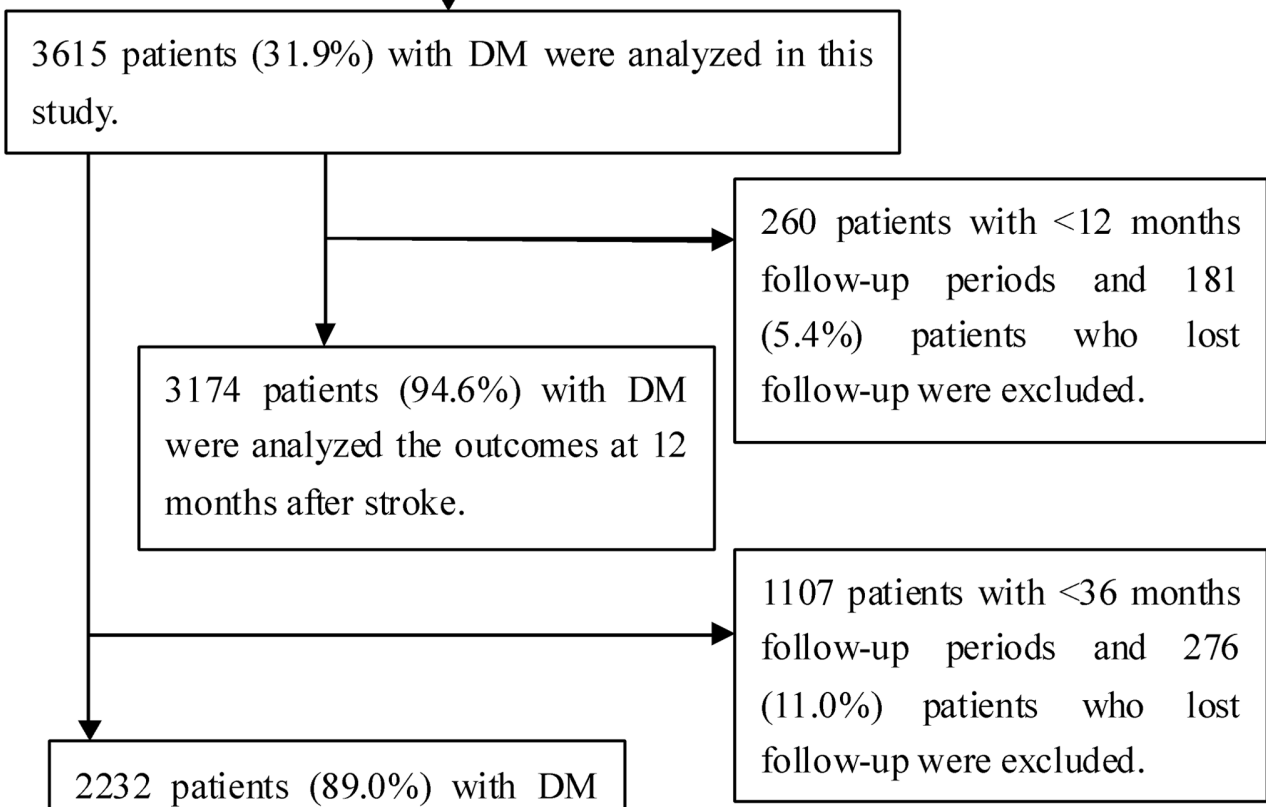

were analyzed the outcomes at 36 months after stroke. 
evidence for this association among elderly patients remains controversial. A report from China demonstrated that DM independently predicted poor outcomes within 6 months after AIS in Chinese patients (Wang et al., 2013). However, differences in long-term outcomes among elderly stroke patients with DM have not been established.

Therefore, in this study, we aimed to evaluate differences in long-term outcomes between younger patients ( $<75$ years old) and elderly patients ( $\geq 75$ years old) with diabetes following AIS from a hospital-based stroke registry in Tianjin, China.

\section{MATERIALS AND METHODS}

All consecutive patients with AIS who were hospitalized in three stroke units in Tianjin, China between January 2006 and September 2014 were recruited for this study. Stroke was defined according to the World Health Organization's criteria, and a diagnosis of AIS was confirmed in all patients based on neuroimaging evidence (Banks and Marotta, 2007). Those patients diagnosed with transient ischemic attack were excluded. DM was defined by a previous or new-onset physician diagnosis of DM, or use of hypoglycemic medications.

The ethics committee of Tianjin Medical University General Hospital approved the study, and patients or their next of kin provided written informed consent for participation in accordance with the Declaration of Helsinki.

Data were collected prospectively according to a standardized procedure. Ischemic stroke subtypes, neurological deficits, level of disability at the time of admission, stroke severity, and stroke risk factors were recorded. Levels of total cholesterol (TC), triglycerides (TG), high-density lipoprotein cholesterol (HDL-C), low-density lipoprotein cholesterol (LDL-C), fasting glucose (FG), and glycosylated hemoglobin ( $\mathrm{HbA} 1)$ at admission also were recorded. During the follow-up period, data on AIS outcomes, including all-cause death, dependency, and recurrence were assessed.

According to the Trial of Org 10172 in Acute Stroke Treatment (TOAST) criteria, ischemic stroke subtypes were classified according to etiology as stroke due to large artery atherothrombosis (LAA), stroke due to cardioembolism (CE), stroke due to small artery occlusion (SAO), stroke of other determined etiology, and stroke of undetermined etiology (Murray and Lopez, 1997). Neurological deficits were assessed using the National Institutes of Health stroke scale (NIHSS; Marini et al., 2004), and the level of disability was measured using the Barthel index (BI; Gur et al., 2012) and modified Rankin scale (mRS; Olindo et al., 2003). Stroke severity was categorized into three groups based on the NIHSS score: mild (NIHSS: $\leq 7$ ), moderate (NIHSS: $8-16$ ), and severe (NIHSS: $\geq 17$ ) (Deng et al., 2012).

Risk factors for stroke included a medical history of hypertension, dyslipidemia, atrial fibrillation (AF), and obesity (body mass index $\geq 30 \mathrm{~kg} / \mathrm{m}^{2}$ ); and modifiable lifestyle factors, including current smoking status and alcohol consumption.

Outcome measures for stroke were mortality, recurrence, and dependency rates 12 and 36 months after AIS. Death was defined
TABLE 1 | Demographical and clinical characteristics in ischemic stroke patients with DM by age.

\begin{tabular}{|c|c|c|c|}
\hline Characteristics & Younger group & Elderly group & $P$ \\
\hline Gender, $n(\%)$ : & 2, $923(80.9)$ & $692(19.1)$ & $<0.001$ \\
\hline Men & 1, 852 (83.3) & $371(16.7)$ & \\
\hline Women & $1,071(76.9)$ & $321(23.1)$ & \\
\hline \multicolumn{4}{|l|}{ Total } \\
\hline \multicolumn{4}{|l|}{ TOAST classification, $n$ (\%): } \\
\hline Atherothrombotic & 2, $066(71.1)$ & 467 (68.9) & 0.099 \\
\hline Small artery disease & 678 (23.3) & 139 (20.5) & 0.079 \\
\hline Cardiac embolism & $73(2.5)$ & 65 (9.6) & $<0.0001$ \\
\hline Others determined etiology & $47(1.6)$ & $2(0.3)$ & 0.007 \\
\hline Undetermined etiology & $42(1.4)$ & $5(0.7)$ & 0.136 \\
\hline \multicolumn{4}{|l|}{ Stroke severity, $n(\%)$ : } \\
\hline Mild & $1,918(65.6)$ & $379(54.8)$ & $<0.0001$ \\
\hline Moderate & $772(26.4)$ & $218(31.5)$ & 0.007 \\
\hline Severe & $233(8.0)$ & 95 (13.7) & $<0.0001$ \\
\hline \multicolumn{4}{|l|}{ Neurological function: } \\
\hline NIHSS & $6(6)$ & 7 (9) & $<0.001$ \\
\hline $\mathrm{BI}$ & $60(50)$ & $50(50)$ & $<0.001$ \\
\hline $\mathrm{mRS}$ & $3(2)$ & $4(1)$ & $<0.001$ \\
\hline \multicolumn{4}{|l|}{ Laboratory examination: } \\
\hline Total cholesterol & $5.04(1.13)$ & $5.01(1.20)$ & 0.533 \\
\hline Triglyceride & $1.93(1.44)$ & $1.56(0.84)$ & $<0.001$ \\
\hline High-density lipoprotein cholesterol & $1.01(0.25)$ & $1.05(0.26)$ & $<0.001$ \\
\hline Low-density lipoprotein cholesterol & $3.10(0.88)$ & $3.11(0.94)$ & 0.668 \\
\hline
\end{tabular}

TABLE 2 | The prevalence of risk factors in ischemic stroke patients with DM by age.

\begin{tabular}{lcrc}
\hline $\begin{array}{l}\text { Previous history of } \\
\text { diseases and risk factors }\end{array}$ & Younger group & Elderly group & $\boldsymbol{P}$ \\
\hline Hypertension & $2,298(78.6)$ & $515(74.4)$ & 0.017 \\
Atrial fibrillation & $144(4.9)$ & $94(13.6)$ & $<0.00001$ \\
Artery stenosis & $804(27.5)$ & $186(26.9)$ & 0.739 \\
Dyslipidemias & $1,135(38.8)$ & $202(29.2)$ & $<0.001$ \\
Obesity & $487(16.7)$ & $130(18.8)$ & 0.182 \\
Current smoking & $1,078(36.9)$ & $110(15.9)$ & $<0.001$ \\
Alcohol consumption & $522(17.9)$ & $32(4.6)$ & $<0.001$ \\
\hline
\end{tabular}

as all-cause mortality at the corresponding time points after hospital admission. Stroke recurrence was defined as any newonset vascular event, including stroke, myocardial infarction, and venous thrombosis, at least 30 days after stroke. Dependency was defined as an mRS score $\geq 3$ (Fonarow et al., 2010). Mortality rates at 12 and 36 months after AIS were calculated as the number of all-cause deaths within 12 and 36 months divided by the total number of patients at the corresponding time points. The recurrence rate was calculated as the proportion of patients with new-onset vascular events, including patients who died of vascular events, during the follow-up period. The dependency rate was calculated as the number of patients with an mRS score $\geq 3$ divided by the total number of stroke survivors at 12 and 36 months after AIS. 
All patients were categorized into two groups by age: younger group ( $<75$ years old) and elderly group ( $\geq 75$ years old). All continuous variables, which included age, NIHSS, BI, mRS, and laboratory values (TC, TG, HDL-C, LDL-C, FG, and HbA1) are presented as the mean (standard deviation) or median (interquartile range, IQR) and compared between groups using the Student's $t$-test or Mann-Whitney $U$ test. All categorical variables, including ischemic stroke subtype, stroke severity, and stroke risk factors, are presented as the number (percentage); the differences between groups for categorical variables were analyzed using the Chi-squared test. A multivariate logistic regression analysis was performed to assess factors associated with stroke outcomes by adjusting for covariates (including stroke subtype, severity, and risk factors). The results of the multivariate analysis are presented as adjusted odds ratios (ORs) with 95\% confidence intervals (CIs). All statistical analyses were performed using SPSS version 15.0 (SPSS Inc., Chicago, IL, USA), and $P$-values $<0.05$ resulting from two-tailed tests were considered statistically significant.

\section{RESULTS}

During the study period, 11,330 consecutive patients with AIS were hospitalized in three stroke units. Of these patients, 7,715 patients $(68.1 \%)$ were excluded because they did not have DM; therefore, 3,615 patients $(31.9 \%)$ were included in the study. A total of 3,174 patients (94.6\%) were analyzed at 12 months after excluding 181 patients (5.4\%) who were lost to follow-up among 3,355 patients with a sufficient follow-up time of 12 months. Similarly, 2,232 patients $(89.0 \%)$ were analyzed at 36 months after excluding 276 patients (11.0\%) who were lost to follow-up among 2,508 patients with a sufficient follow-up time of 36 months (Figure 1).

The elderly group included 692 patients (19.1\%), more than half of whom (53.6\%) were men. Elderly patients were more likely than younger patients to have a TOAST classification of CE (9.6 vs. $2.5 \% ; P<0.00001)$. The proportion of patients with moderate and severe stroke were significantly higher in the elderly group than in the younger group ( 31.5 vs. $26.4 \%, P=0.007$ for moderate stroke; 13.7 vs $8.0 \%, P<0.00001$ for severe stroke). Similarly, median NIHSS and mRS scores were higher, whereas BI scores were lower, in elderly patients compared with younger patients (all $P<0.001$, Table 1).

The prevalence of hypertension, dyslipidemia, current smoking, and alcohol consumption was lower in elderly patients compared to younger patients (Table 2); however, an opposite trend was observed for the prevalence of AF (13.6 vs. $4.9 \%, P<0.001)$. There were no significant differences in the prevalence of artery stenosis and obesity between the elderly and younger patients.

Mortality, dependency, and recurrence rates at 12 months after stroke were $19.0,48.5$, and $20.9 \%$ in the elderly group and $7.4,30.9$, and $15.4 \%$ in the younger group, respectively (all $P<0.05)$. The corresponding rates at 36 months after stroke were $35.4,78.7$, and $53.8 \%$ in the elderly group and $13.7,61.7$, and $43.0 \%$ in the younger group, respectively (all $P<0.001$ ). After adjusting for stroke subtypes, severity, and risk factors, mortality, dependency, and recurrence rates at 12 and 36 months after stroke were significantly higher in the elderly group than in the younger group. OR $(95 \% \mathrm{CI})$ at 12 months after stroke was 2.18 (1.64-2.89, $P<0.001)$ for mortality, 1.81 (1.49-2.20, $P<0.001)$ for dependency, and $1.37(1.06-1.76, P=0.016)$ for recurrence, respectively. The corresponding values at 36 months after stroke were 3.10 (2.35-4.08, $P<0.001)$ for mortality, 2.04 (1.57-2.34, $P<0.001)$ for dependency, and $1.40(1.07-1.85, P=0.016)$ for recurrence, respectively (Table 3 ).

\section{DISCUSSION}

In this study, we assessed and compared the outcomes and associated risk factors at 12 and 36 months after AIS between younger patients ( $<75$ years old) and elderly patients $(\geq 75$ years old) with DM in China.

Diabetes mellitus is an independent risk factor for ischemic stroke, as the relative risk of ischemic stroke in patients with $\mathrm{DM}$ is $1.8-6.0$ times higher than in patients without DM (Saposnik et al., 2008). Moreover, the prevalence of DM ranges from 21 to $44 \%$ in patients with AIS (Soares et al., 2011; Li et al., 2013). The China National Stroke Registry reported a 26.99\% prevalence of DM overall (Schulz and Rothwell, 2003).

\begin{tabular}{|c|c|c|c|c|c|c|}
\hline \multirow[t]{2}{*}{ Outcomes } & \multirow[t]{2}{*}{ Younger group } & \multirow[t]{2}{*}{ Elderly group } & \multicolumn{2}{|c|}{ Unadjusted } & \multicolumn{2}{|c|}{ Adjusted $^{\dagger}$} \\
\hline & & & OR (95\% Cl) & $P$ & OR (95\% Cl) & $\boldsymbol{P}$ \\
\hline \multicolumn{7}{|l|}{12 months: } \\
\hline Mortality & $189(7.4)$ & 116 (19.0) & 2.95 (2.30-3.79) & $<0.001$ & 2.18 (1.64-2.89) & $<0.001$ \\
\hline Dependency & $786(30.7)$ & $296(48.5)$ & $2.13(1.78-2.55)$ & $<0.001$ & $1.81(1.49-2.20)$ & $<0.001$ \\
\hline Recurrence & $367(15.4)$ & $102(20.9)$ & $1.45(1.14-1.86)$ & 0.003 & $1.37(1.06-1.76)$ & 0.016 \\
\hline \multicolumn{7}{|l|}{36 months: } \\
\hline Mortality & $248(13.7)$ & $151(35.4)$ & $3.44(2.70-4.36)$ & $<0.001$ & $3.10(2.35-4.08)$ & $<0.001$ \\
\hline Dependency & $1,113(61.7)$ & $336(78.7)$ & $2.30(1.79-2.95)$ & $<0.001$ & $2.04(1.57-2.64)$ & $<0.001$ \\
\hline Recurrence & $636(43.0)$ & $141(53.8)$ & $1.54(1.19-2.01)$ & $<0.001$ & $1.40(1.07-1.85)$ & 0.016 \\
\hline
\end{tabular}

*OR indicated the risks in elderly group reference as younger group. ${ }^{\dagger}$ Indicated adjusted by gender, stroke subtype, severity, and risk factors. 
Consistent with previous studies, we found a 31.9\% prevalence of DM among patients with AIS, which was higher than the prevalence determined from the China National Stroke Registry. Different databases of stroke patients between studies may partly explain differences in the frequency of stroke patients with DM.

Previous studies have indicated that ischemic stroke greatly affects the older population (Lovett et al., 2004; Rothwell et al., 2005; Lloyd-Jones et al., 2009; Feigin et al., 2014). Several studies have reported different trends in the prevalence of hypertension, DM, and AF (Olindo et al., 2003; Bhalla et al., 2004; Marini et al., 2004; Gur et al., 2012) among elderly individuals. A study based on a multicenter stroke registry in China reported that patients aged 80 years and older were more likely to have a stroke with a TOAST classification of CE (11.6\%). Furthermore, there were higher rates of hypertension (72.1\%) and $\mathrm{AF}(23.4 \%)$ and lower rates of DM (17.5\%), dyslipidemia (5.6\%), current smoking status (22.8\%), and heavy drinking (2.5\%) among AIS patients $\geq 80$ years old compared to patients $<80$ years old (Deng et al., 2012). Consistent with these studies, in this study, elderly patients exhibited different clinical features and stroke risk factors than younger patients. The proportions of patients with a TOAST classification of CE, severe stroke, and AF were higher in the elderly group than in the younger group. Younger patients were more likely to have a previous history of hypertension and dyslipidemia and were more likely to be current smokers and alcohol consumers than elderly patients. However, there was no significant difference with respect to artery stenosis or obesity between the two groups.

Previous studies have demonstrated that older patients have worse outcomes after stroke than do younger patients (Lovett et al., 2004; Kimura et al., 2005; Palnum et al., 2008; Tu et al., 2010,2011). A study conducted in China reported a mortality rate of $34.78 \%$, a dependency rate of $43.81 \%$, and a recurrence rate of $36.02 \%$ at 12 -month follow-up among AIS patients $\geq 80$ years old (Deng et al., 2012). Another study reported that the 1-year case-fatality rate and disability rate in patients $\geq 80$ years old were 33.8 and $37.8 \%$, respectively (Tu et al., 2011). Findings from a multivariate analysis in another study revealed that TOAST classification of CE and LAA and moderate and severe stroke were associated with mortality and recurrence 3 months after stroke; moderate and severe stroke also were associated with dependency 3 months after stroke. In addition, moderate and severe stroke were significantly associated with mortality and dependency at 12 months (Bereczki et al., 2009).

Several studies have suggested that DM is associated with a higher stroke mortality rate (Zhang et al., 2008; Soares et al., 2011), but this association was not observed in other studies (Tuttolomondo et al., 2008; Weiss et al., 2013). Furthermore, many studies have indicated that DM was an important predictive factor for dependency (Zhang et al., 2008; Eriksson et al., 2012; Tanaka et al., 2013) and recurrence rates (Sun et al., 2009; Kong et al., 2010; Callahan et al., 2011) following stroke. However, studies indicated that treatment DM using antidiabetic before or after stroke onset has a meaningful effect on stroke outcome in patients with DM comparing those patients without DM (Kunte et al., 2007; Tziomalos et al., 2015).
Age emerged as a highly significant inverse predictor of good functional outcome after ischemic stroke, it was independent of stroke severity, characteristics, and complications. (Knoflach et al., 2012). This study found that mortality, dependency, and recurrence rates were significantly higher in the elderly group than in the younger group among stroke patients with DM at both 12 and 36 months. The mortality, dependency, and recurrence rates in the elderly group were $2.2-, 1.8-$, and $1.4-$ fold higher, respectively, than the corresponding rates in the younger group at 12 months, and were 3.1-, 2.0-, and 1.4-fold higher, respectively, than the corresponding rates in the younger group at 36 months. Age was a predictor of poor long-term outcomes among stroke patients with DM, it was independent of the benefit from treatment using antidiabetic. Worse longterm outcomes in elderly stroke patients with DM may be explained by the limited application of secondary measures for stroke prevention and poor health care services for elderly patients.

There are several limitations to this study. First, all patients were from the local hospital in Tianjin, China, resulting in a limited representation of the general population. Second, all patients were from the local university hospital or neurological specialty hospital, and accordingly, the proportion of patients with severe stroke was higher in this study than in previous studies. However, we adjusted the results by gender, stroke subtype, stroke severity, and risk factors in the multivariate analysis, thus addressing the effect of stroke severity on patient outcomes in our results. Third, pre-stroke information, including medication usage and complications such as pneumonia and urinary tract infection, were not analyzed in this study; therefore, we were unable to assess the impact of these factors on outcomes among elderly patients.

\section{CONCLUSION}

This is the first study to assess the long-term (12 and 36 months) outcomes following AIS between younger and elderly AIS patients with DM in China. Mortality, dependency, and recurrence rates were significantly higher in the elderly group than in the younger group at both 12 and 36 months after AIS. The relationship between age and outcomes remained even after adjusting for stroke subtypes, severity, and risk factors. Age was a predictor of poor long-term outcomes among stroke patients with DM, it was independent of the benefit from treatment using antidiabetic. Poor outcomes in elderly patients may be partly explained by the higher frequency of women, less frequent use of secondary measures to prevent stroke, and poor health care within the elderly population. Thus, management and secondary prevention should be emphasized in elderly patients with DM in China to reduce mortality, recurrence, and dependency after stroke.

\section{AUTHOR CONTRIBUTIONS}

$\mathrm{BL}$, JW, and ZA made substantial contributions to the conception and design of the study. XL, TW, YL, HG, XG, YZ, and WZ 
made substantial contributions to the acquisition, analysis, and interpretation of data. XN and JW substantially contributed to the analysis and interpretation of data. BL, JW, and ZA supervised the study. BL and ZA were involved in obtaining funding for the study. All authors contributed to the drafting of the manuscript and approved the final version.

\section{REFERENCES}

Banks, J. L., and Marotta, C. A. (2007). Outcomes validity and reliability of the modified Rankin scale: implications for stroke clinical trials: a literature review and synthesis. Stroke 38, 1091-1096. doi: 10.1161/01.STR.0000258355.23810.c6

Bereczki, D., Mihálka, L., Fekete, I., Valikovics, A., Csépány, T., Fülesdi, B., et al. (2009). The debrecen stroke database: demographic characteristics, risk factors, stroke severity and outcome in 8088 consecutive hospitalized patients with acute cerebrovascular disease. Int. J. Stroke 4, 335-339. doi: 10.1111/j.17474949.2009.00332.x

Bhalla, A., Grieve, R., Tilling, K., Rudd, A. G., and Wolfe, C. D. (2004); BIOMED II European study of stroke care. older stroke patients in Europe: stroke care and determinants of outcome. Age Ageing 33, 618-624. doi: 10.1093/ageing/afh219

Brott, T., Adams, H. P Jr., Olinger, C. P., Marler, J. R., Barsan, W. G., Biller, J., et al. (1989). Measurements of acute cerebral infarction: a clinical examination scale. Stroke 20, 864-870. doi: 10.1161/01.STR.20.7.864

Callahan, A., Amarenco, P., Goldstein, L. B., Sillesen, H., Messig, M., Samsa, G. P., et al. (2011). Risk of stroke and cardiovascular events after ischemic stroke or transient ischemic attack in patients with type 2 diabetes or metabolic syndrome: secondary analysis of the stroke prevention by aggressive reduction in cholesterol levels (SPARCL) trial. Arch. Neurol. 68, 1245-1251. doi: 10.1001/archneurol.2011.146

Deng, Y. X., Wang, Y. L., Gao, B. Q., Wang, C. X., Zhao, X. Q., Liu, L. P., et al. (2012). Age differences in clinical characteristics, health care, and outcomes after ischemic stroke in China. CNS Neurosci. Ther. 18, 819-826. doi: 10.1111/j.1755-5949.2012.00378.x

Di Carlo, A., Lamassa, M., Pracucci, G., Basile, A. M., Trefoloni, G., Vanni, P., et al. (1999). Stroke in the very old: clinical presentation and determinants of 3month functional outcome: a European perspective: European BIOMED Sstudy of Sstroke Ccare Ggroup. Stroke 30, 2313-2319. doi: 10.1161/01.STR.30.11.2313

Eriksson, M., Carlberg, B., and Eliasson, M. (2012). The disparity in long-term survival after a first stroke in patients with and without diabetes persists: the Northern Sweden MONICA study. Cerebrovasc. Dis. 34, 153-160. doi: $10.1159 / 000339763$

Feigin, V. L., Forouzanfar, M. H., Krishnamurthi, R., Mensah, G. A., Connor, M., Bennett, D. A., et al. (2014). Global and regional burden of stroke during 19902010: findings from the Global Burden of Disease Study 2010. Lancet 383, 245-254. doi: 10.1016/S0140-6736(13)61953-4

Fonarow, G. C., Reeves, M. J., Zhao, X., Olson, D. M., Smith, E. E., Saver, J. L., et al. (2010). Age-related differences in characteristics, performance measures, treatment trends, and outcomes in patients with ischemic stroke. Circulation 121, 879-891. doi: 10.1161/CIRCULATIONAHA.109.892497

Gur, A. Y., Tanne, D., Bornstein, N. M., Milo, R., Auriel, E., Shopin, L., et al. (2012). Stroke in the very elderly: Characteristics and outcome in patients aged $>85$ years with a first-ever ischemic stroke. Neuroepidemiology 39, 57-62. doi: $10.1159 / 000339362$

Kammersgaard, L. P., Jørgensen, H. S., Reith, J., Nakayama, H., Pedersen, P. M., and Olsen, T. S. (2004). Short- and long-term prognosis for very old stroke patients: the Copenhagen Stroke Study. Age. Ageing 33, 149-154. doi: 10.1093/ageing/afh052

Kelly-Hayes, M., Beiser, A., Kase, C. S., Scaramucci, A., D’Agostino, R. B., and Wolf, P. A. (2003). The influence of gender and age on disability following ischemic stroke: the Framingham study. J. Stroke Cerebrovasc. Dis. 12, 119-126. doi: 10.1016/S1052-3057(03)00042-9

Kimura, K., Minematsu, K., and Yamaguchi, T., (2005). Japan multicenter Stroke Investigators' Collaboration (J-MUSIC). (2005) AF as a predictive factor for severe stroke and early death in 15,831 patients with acute ischemic stroke. J. Neurol. Neurosurg. Psychiatry 76, 679-683. doi: 10.1136/jnnp.2004.048827

\section{FUNDING}

This work was supported by Tianjin Health Bureau of Science and Technology Fund Key Projects (contract: KY12, and 2013KG120), a Local Key Project of Binhai New District, Tianjin of China, and The Project of Prevention and Treatment System on Cerebrovascular Disease in Dagang Oilfield, China.

Knoflach, M., Matosevic, B., Rücker, M., Furtner, M., Mair, A., Wille, G., et al. (2012). Functional recovery after ischemic stroke-a matter of age: data from the Austrian Stroke Unit Registry. Neurology 78, 279-285. doi: 10.1212/WNL.0b013e31824367ab

Kong, F. Y., Tao, W. D., Hao, Z. L., and Liu, M. (2010). Predictors of oneyear disability and death in Chinese hospitalized women after ischemic stroke. Cerebrovasc. Dis. 29, 255-262. doi: 10.1159/000267852

Kunte, H., Schmidt, S., Eliasziw, M., del Zoppo, G. J., Simard, J. M., Masuhr, F., et al. (2007). Sulfonylureas improve outcome in patients with type 2 diabetes and acute ischemic stroke. Stroke 38, 2526-2530. doi: 10.1161/STROKEAHA.107.482216

Li, S., Zhao, X., Wang, C., Liu, L., Liu, G., Wang, Y., et al. (2013). Risk factors for poor outcome and mortality at 3 months after the ischemic stroke in patients with atrial fibrillation. J. Stroke Cerebrovasc. Dis. 22, e419-e425. doi: 10.1016/j.jstrokecerebrovasdis.2013.04.025

Lloyd-Jones, D., Adams, R., Carnethon, M., De Simone, G., Ferguson, T. B., Flegal K., et al. (2009). Heart disease and stroke statistics2009 update: a report from the american heart association statistics committee and stroke statistics subcommittee. Circulation 119, 480-486. doi: 10.1161/CIRCULATIONAHA.108.191259

Lovett, J. K., Coull, A. J., and Rothwell, P. M. (2004). Early risk of recurrence by subtype of ischemic stroke in population-based incidence studies. Neurology 62 , 569-573. doi: 10.1212/01.WNL.0000110311.09970.83

Mahoney, F. I., and Barthel, D. W. (1965). Functional evaluation: The Barthel Index. Md. State Med. J. 14, 61-65.

Marini, C., Baldassarre, M., Russo, T., De Santis, F., Sacco, S., Ciancarelli, I., et al. (2004). Burden of first-ever ischemic stroke in the oldest old: evidence from a population-based study. Neurology 62, 77-81. doi: 10.1212/01.WNL.0000101461.61501.65

MONICA Project (Monitoring Trends, and Determinants in Cardiovascular Disease) (1988). A major international collaboration. WHO MONICA. (Project) Principal Investigators. J. Clin. Epidemiol. 41, 105-114.

Murray, C. J. L., and Lopez, A. D. (1997). Alternative projections of mortality and disability by cause 1990-2020: Global Burden of Disease Study. Lancet 349, 1498-1504. doi: 10.1016/S0140-6736(96)07492-2

National Bureaus of Statistics of the People's Republic of China (2014). China Statistical Yearbook 2013. Beijing: China Statistics Press.

Olindo, S., Cabre, P., Deschamps, R., Chatot-Henry, C., René-Corail, P., Fournerie, P., et al. (2003). Acute stroke in the very elderly epidemiological features, stroke subtypes, management, and outcome in Martinique, French West Indies. Stroke 34, 1593-1597. doi: 10.1161/01.STR.0000077924. 71088.02

Palnum, K. D., Petersen, P., Sørensen, H. T., Ingeman, A., Mainz, J., Bartels, P., et al. (2008). Older patients with acute stroke in Denmark: quality of care and short-term mortality: a nationwide follow-up study. Age. Ageing 37, 90-95. doi: 10.1093/ageing/afm134

Peilin, L., Guangjin, C., and Yi, Z. (2014). Blue Book of China society: Society of China Analysis and Forecast. Beijing: Chinese Academy of Social Sciences Press.

Rankin, J. (1957). Cerebral vascular accidents in patients over the age of 60. II. Prognosis. Scott. Med. J. 2, 200-215.

Recommendations on Stroke Prevention, Diagnosis, and Therapy (1989). Report of the WHO task force on stroke and other cerebrovascular disorders. Stroke 20, 1407-1431.

Rothwell, P. M., Coull, A. J., Silver, L. E., Fairhead, J. F., Giles, M. F., Lovelock, C. E., et al. (2005). Oxford Vascular Study. Population-based study of eventrate, incidence, case fatality, and mortality for all acute vascular events in all arterial territories (Oxford Vascular Study). Lancet 366, 1773-1783. doi: $10.1016 /$ S0140-6736(05)67702-1 
Saposnik, G., Hill, M. D., O’Donnell, M., Fang, J., Hachinski, V., Kapral, M. K., et al. (2008). Variables associated with 7-day, 30-day, and 1-year fatality after ischemic stroke. Stroke 39, 2318-2324. doi: 10.1161/STROKEAHA.107.510362

Schulz, U. G., and Rothwell, P. M. (2003). Differences in vascular risk factors between etiological subtypes of ischemic stroke: importance of populationbased studies. Stroke 34, 2050-2059. doi: 10.1161/01.STR.0000079818.08343.8C

Soares, I., Abecasis, P., and Ferro, J. M. (2011). Outcome of first-ever acute ischemic stroke in the elderly. Arch. Gerontol. Geriat. 53, e81-e87. doi: 10.1016/j.archger.2010.06.019

Sun, Y., Paul, M., and Toh, H. S. (2009). Impact of diabetes mellitus (DM) on the health-care utilization and clinical outcomes of patients with stroke in Singapore. Value Health 12, S101-S105. doi: 10.1111/j.1524-4733.2009.00639.x

Tanaka, R., Ueno, Y., Miyamoto, N., Yamashiro, K., Tanaka, Y., Shimura, H., et al. (2013). Impact of diabetes and prediabetes on the short-term prognosis in patients with acute ischemic stroke. J. Neurol. Sci. 332, 45-50. doi: 10.1016/j.jns.2013.06.010

Tu, H. T., Campbell, B. C., Christensen, S., Collins, M., De Silva, D. A., Butcher, K. S., et al. (2010). Pathophysiological determinants of worse stroke outcome in atrial fibrillation. Cerebrovasc. Dis. 30, 389-395. doi: 10.1159/000316886

Tu, H. T., Campbell, B. C., Churilov, L., Kalman, J. M., Lees, K. R., Lyden, P. D., et al. (2011). Frequent early cardiac complications contribute to worse stroke outcome in atrial fibrillation. Cerebrovasc. Dis. 32, 454-460. doi: $10.1159 / 000332028$

Tuttolomondo, A., Pinto, A., Salemi, G., Di Raimondo, D., Di Sciacca, R., Fernandez, P., et al. (2008). Diabetic and non-diabetic subjects with ischemic stroke: differences, subtype distribution and outcome. Nutr. Metab. Cardiovasc. Dis. 18, 152-157. doi: 10.1016/j.numecd.2007.02.003

Tziomalos, K., Bouziana, S. D., Spanou, M., Kostaki, S., Papadopoulou, M., Giampatzis, V., et al. (2015). Prior treatment with dipeptidyl peptidase 4 inhibitors is associated with better functional outcomeand lower in-hospital mortality in patients with type 2 diabetes mellitus admitted with acute ischaemic stroke. Diab. Vasc. Dis. Res. 12, 463-466. doi: 10.1177/1479164115597867
Ullberg, T., Zia, E., Petersson, J., and Norrving, B. (2015). Changes in functional outcome over the first year after stroke: an observational study from the Swedish Sstroke Rregister. Stroke 46, 389-394. doi: 10.1161/STROKEAHA.114. 006538

Wang, J., An, Z., Li, B., Yang, L., Tu, J., Gu, H., et al. (2015). Increasing stroke incidence and prevalence of risk factors in a low-income Chinese population. Neurology 84, 374-381. doi: 10.1212/WNL.0000000000 001175

Wang, Z., Li, J., Wang, C., Yao, X., Zhao, X., Wang Y., et al. (2013). Gender differences in 1-year clinical characteristics and outcomes after stroke: Results from the China National Stroke Registry. PLOS ONE 8:e56459. doi: 10.1371/journal.pone.0056459

Weiss, A., Beloosesky, Y., Kenett, R. S., and Grossman, E. (2013). Systolic blood pressure during acute stroke is associated with functional status and long-term mortality in the elderly. Stroke 44, 2434-2440. doi: 10.1161/STROKEAHA.113.001894

Zhang, Y., Reilly, K. H., Tong, W., Xu, T., Chen, J., Bazzano, L. A., et al. (2008). Blood pressure and clinical outcome among patients with acute stroke in Inner Mongolia, China. J. Hypertens. 26, 1446-1452. doi: 10.1097/HJH.0b013e328300a24a

Conflict of Interest Statement: The authors declare that the research was conducted in the absence of any commercial or financial relationships that could be construed as a potential conflict of interest.

Copyright (c) 2016 Long, Lou, Gu, Guo, Wang, Zhu, Zhao, Ning, Li, Wang and An. This is an open-access article distributed under the terms of the Creative Commons Attribution License (CC BY). The use, distribution or reproduction in other forums is permitted, provided the original author(s) or licensor are credited and that the original publication in this journal is cited, in accordance with accepted academic practice. No use, distribution or reproduction is permitted which does not comply with these terms. 